Disclosure of Interests: Eri Oguro: None declared, Yuji Yoshida: None declared, Kentaro Kuzuya: None declared, Yasutaka Okita: None declared, Hidetoshi Matsuoka: None declared, Satoru Teshigawara: None declared, Maiko Yoshimura: None declared, Kentaro Isoda: None declared, Yoshinori Harada: None declared, Shiro Ohshima Grant/research support from: AbbVie, Eisai, Asahikasei, Speakers bureau: AbbVie, Eisai, Bristol-Meyers, Novartis, Astellas, Nippon-Kayaku, Pfizer, UCB, Ayumi, Daiichi-Sankyo, Takeda, Tanabe-Matsubishi, Chugai, Jun Hashimoto: None declared, Yukihiko Saeki: None declared

DOI: 10.1136/annrheumdis-2019-eular.5581

\section{FRI0113 COMPARISON OF INFECTION-RELATED HOSPITALIZATION COSTS IN PATIENTS WITH RHEUMATOID ARTHRITIS (RA) TREATED WITH ABATACEPT OR OTHER TARGETED DISEASE- MODIFYING ANTI-RHEUMATIC DRUGS (TDMARDS)}

Damemarie Paul, Francis Lobo, Vardhaman Patel, Dhaval Patil. Bristol-Myers Squibb, US HEOR, Lawrence Township, United States of America

Background: Costs due to differences in risk of hospitalized infection associated with targeted disease-modifying anti-rheumatic drugs (tDMARDs) in patients with RA have not been evaluated.

Objectives: Compare the risk and cost of infection-related hospitalizations in tumor necrosis factor inhibitor (TNFi)-experienced RA patients subsequently receiving tDMARDs in the US.

Methods: A retrospective, observational study was conducted with 2 insurance claims databases (MarketScan and PharMetrics; January 1, 2009- June 30, 2017). Analyses were conducted in both datasets individually and in aggregate. The study population was adult TNFi-experienced RA patients initiating a subsequent tDMARD (date of tDMARD therapy=index date). Patients had 12 months of continuous enrollment prior to the index date (baseline period), and were required to have $>1$ inpatient claim or $\geq 2$ outpatient medical claims on 2 different dates with a diagnosis code for RA. Patients with other autoimmune conditions were excluded. Follow-up began with the index date and included $\geq 12$ months ending with the earliest of (1) end of insurance enrollment; (2) end of study period; (3) end of index treatment. Cohorts included (1) abatacept; (2) TNFi: adalimumab, certolizumab pegol, etanercept, golimumab, and infliximab; and (3) other non-TNFi: tocilizumab, rituximab, and tofacitinib. Hospitalized infection costs were measured on a per-patient-per-month (PPPM) basis (2016 USD). Two-part multivariable generalized linear models (GLMs) examined differences in costs. Baseline comorbidities, infection incidence, healthcare costs, payer type, age, gender, and geographic region were used as regression covariates. Log transformation and gamma distribution were applied in GLMs.

Results: Overall, most patients were female $(79 \%)$ with an average age of 52 years. Although a higher percentage $(4.5 \%)$ of patients in the abatacept cohort had a hospital visit for infection in the baseline period compared to TNFi $(2.0 \%, P<0.0001)$ and other non-TNFi $(3.6 \%, P=0.2619)$, the trend reversed in the follow-up period $(2.8 \%$ for abatacept vs $3.7 \%$ for $\mathrm{TNFi}$ and $5.2 \%$ for other non-TNFi; $\mathrm{P}<0.05)$. Regression results indicated a significantly higher risk for hospitalized infection for patients receiving a TNFi [HR: $1.6(95 \% \mathrm{Cl}: 1.1,2.2)]$ or other non-TNFi [HR: 1.9 (95\%: 1.3, 2.8)] vs abatacept. Mean PPPM (95\% Cl) inpatient costs in the follow-up were $\$ 73(\$ 17-\$ 158)$ for abatacept, $\$ 115$ (\$27-\$224) for TNFi, and $\$ 125(\$ 29-\$ 264)$ for other non-TNFi. Difference from baseline to follow-up PPPM inpatient costs was significantly lower for abatacept (difference of $\$ 42$ for TNFi and $\$ 52$ for other non-TNFi, $\mathrm{P}<0.05$ ).

Conclusion: There were significantly lower infection-related hospitalizations and associated costs for TNFi-experienced RA patients who were switched to abatacept compared to patients switched to other therapies. Disclosure of Interests: Damemarie Paul Shareholder of: Bristol-Myers Squibb, Employee of: Damemarie Paul is an employee of Bristol-Myers Squibb., Francis Lobo Shareholder of: Bristol-Myers Squibb, Employee of: Bristol-Myers Squibb, Vardhaman PATEL Employee of: Bristol-Myers Squibb, Dhaval Patil Shareholder of: Bristol-Myers Squibb, Employee of: Bristol-Myers Squibb

DOI: 10.1136/annrheumdis-2019-eular.6270

\section{FRI0114 \\ ABATACEPT IN EARLY RHEUMATOID ARTHRITIS: A SYSTEMATIC LITERATURE REVIEW AND NETWORK META-ANALYSIS}

Damemarie Paul ${ }^{1}$, Leticia Ferri ${ }^{1}$, Grace Crocket $^{1}$, Lauren Mintzer ${ }^{2}$, Mir Sohail Fazeli ${ }^{2} .{ }^{1}$ Bristol-Myers Squibb, Princeton, NJ, United States of America; ${ }^{2}$ Doctor Evidence LLC, Santa Monica, CA, United States of America

Background: Rheumatoid arthritis (RA) is a wide-spread and debilitating disorder that is becoming increasingly relevant in an aging global population. Identifying and treating RA early in disease course is critical for preventing disability and joint damage.

Objectives: The goal of this systematic literature review (SLR) and metaanalysis was to compare the relative efficacy of abatacept (ABA) to other currently recommended therapies for patients with early RA.

Methods: We followed Cochrane guidelines for conducting intervention reviews. Population of interest was adult patients with active RA for $\leq 2$ years treated with recommended therapies per the 2015 ACR guidelines as well as targeted synthetic therapies. Studies of interest were randomized controlled trials (RCTs) and observational studies. Outcomes included ACR50, DAS28, radiographic change, and adverse events where available. A search from January 1998 to June 2018 was performed on MEDLINE ${ }^{\circledR}$, Embase, and the Cochrane CENTRAL databases. Additionally, a hand-search was performed on US and European clinical trials registries from January 2005 to June 2018 and conference proceedings from ACR and EULAR from 2014 to 2018. A Bayesian network metaanalysis (NMA) was performed on the DOC Data ${ }^{\mathrm{TM}}$ platform for the RCTs with reported results on ACR50, DAS28 remission, total withdrawal, and withdrawal due to adverse events.

Results: We identified 90 publications on 69 unique trials reporting efficacy and safety outcomes in patients with early RA, including 43 RCTs and 26 observational studies. The included studies were low risk as assessed by the Cochrane Collaboration's tool for assessing risk of bias. The studies were predominantly double-blind phase III or IV trials. Twenty-eight trials were included in the NMA evaluating ABA $(n=1$ trial), ABA+MTX $(n=2), \quad A D A+M T X(n=6), \quad C T Z+M T X \quad(n=2), \quad \operatorname{ETN}(n=1), \quad$ ETN $+\operatorname{MTX}(n=1), \quad H C Q+S S Z+M T X \quad(n=1), \quad H C Q+S S Z+P r e d+M T X \quad(n=1), \quad$ IFX $+\operatorname{MTX}(n=4), \quad M T X \quad(n=21), \quad$ MPred+MTX $(n=2)$, MPred+Pred+MTX $(n=1)$ Pred $+S S Z+M T X(n=2)$, Pred $+\operatorname{MTX}(n=4)$, Pred $(n=1)$, SSZ $(n=4)$, SSZ $+\operatorname{MTX}(n=2), \quad \operatorname{TCZ}(n=2), \quad \operatorname{TCZ}+\operatorname{MTX}(n=2), \quad$ TOF $(n=2)$, and TOF+MTX $(n=2)$. Abatacept as monotherapy was similar to the combination of $A B A$ and methotrexate for efficacy outcomes, ACR 50 (ABA vs ABA+MTX RR $0.82[95 \% \mathrm{Cl} 0.51-1.35]$ ), and DAS28 Remission (RR $0.76[95 \% \mathrm{Cl} 0.39$ 1.49]), as well as for all-cause withdrawal (RR $1.8[95 \% \mathrm{Cl} 0.91-3.2]$ ) and withdrawal due to adverse events (RR $2.35[95 \% \mathrm{Cl}$ 0.69-7.38]) Both $\mathrm{ABA}$ as monotherapy and $\mathrm{ABA}+\mathrm{MTX}$ were similar to all other comparators (as monotherapy or combination therapy) with respect to main efficacy and safety outcomes. Data reported in observational studies was in concert with the RCT analysis.

Conclusion: The results of this NMA demonstrate similar efficacy between ABA and other biologics both as monotherapy and in combination with traditional DMARDS in early RA. Further investigation and comparison of different treatment options for early RA is warranted as the growing evidence base evolves in favor of using more novel therapies for RA $\mathrm{ABA}=$ abatacept; $\mathrm{ADA}=$ adalimumab; $\mathrm{CTZ}=$ certolizumab; $\mathrm{ETN}=$ etanercept; $\mathrm{HCQ}=$ hydroxychloroquine, IFX= infliximab, MPred= methylprednisolone, $\mathrm{MTX}=$ methotrexate; Pred=prednisone, $\mathrm{SSZ}=$ sulfasalazine, $\mathrm{TCZ}=$ tocilizumab, TOF=tofacitinib

Disclosure of Interests: Damemarie Paul Shareholder of: Bristol-Myers Squibb, Employee of: Damemarie Paul is an employee of Bristol-Myers Squibb., Leticia Ferri Shareholder of: Bristol-Myers Squibb, Employee of Bristol-Myers Squibb, Grace Crocket Consultant for: Grace Crocket is a consultant for Bristol-Myers Squibb., Lauren Mintzer Grant/research support from: Lauren Mintzer is an employee of Doctor Evidence LLC, and the study was funded by Bristol-Myers Squibb., Mir Sohail Fazeli Grant research support from: Mir Sohail Fazeli is an employee of Doctor Evidence LLC, and the study was funded by Bristol-Myers Squibb. DOI: 10.1136/annrheumdis-2019-eular.5179

\section{FRI0115 \\ TRAJECTORIES OF THE EQ-5D SCORE AMONG A LARGE COHORT OF RHEUMATOID ARTHRITIS PATIENTS TREATED WITH BIOLOGICAL DMARDS USING THE IORRA COHORT}

Kumiko Saka $^{1}$, Eiichi Tanaka ${ }^{1}$, Eisuke Inoue ${ }^{2}$, Mai Abe $^{1}$, Mika Kawano ${ }^{1}$, Eri Sugano $^{1}$, Naohiro Sugitani ${ }^{1,3}$, Moeko Ochiai ${ }^{1}$, Yoko Shimizu $^{1}$, Rei Yamaguchi ${ }^{1}$, Naoki Sugimoto ${ }^{1}$, Katsunori Ikari ${ }^{1}$, Ayako Nakajima ${ }^{3}$, Atsuo Taniguchi ${ }^{1}$, Hisashi Yamanaka'. ${ }^{1}$ Tokyo Women's Medical University, Tokyo, Japan; ${ }^{2}$ St Mrianna University School of Medicine, Kanagawa, Japan; ${ }^{3}$ Mie University Hospital, Mie, Japan

Background: Patient-reported outcomes are important for evaluating the disease status of patients with rheumatoid arthritis (RA). The EuroQol five-dimensional descriptive system (EQ-5D) has been used to assess health-related quality of life (QOL) in clinical research and pharmacoeconomic studies. RA is a chronic disease associated with pain, fatigue, dis ability, and functional loss, which can markedly decrease patient QOL. 
The treatment strategies for RA and the QOL of RA patients, which is evaluated in daily practice using the EQ-5D, have changed significantly since the introduction of biological disease-modifying anti-rheumatic drugs (bDMARDs).

Objectives: To identify patient subsets with distinct EQ-5D trajectories among RA patients taking bDMARDs, and to examine the clinical features of patients whose QOL improved since bDMARD use in daily practice.

Methods: Since October 2000, we have established a large observational cohort of RA patients at our institute Institute Of Rheumatology, Rheumatoid Arthritis (IORRA). Essentially, all RA patients who attend our clinic are given questionnaires, including the EQ-5D, Disease Activity Score 28 (DAS28), and the Japanese version of the Health Assessment Questionnaire (J-HAQ), every 6 months. More than 5,000 RA patients are included in this cohort, of whom 785 patients who received bDMARDs for at least 3 years were enrolled in this study. The EQ-5D scores of these 785 patients were recorded biannually for 3 years, and latent class analysis of the temporal trends in the EQ-5D score based on posterior probabilities was performed after initiation of bDMARDs. The clinical characteristics of each latent class were then compared

Results: The 785 patients (107 taking infliximab, 341 etanercept, 100 tocilizumab, 131 abatacept, 90 golimumab, and 16 certolizumab pegol) were classified into four classes based on time-related changes in their EQ-5D scores: Class $1(n=160)$, patients with a consistently low score $<0.6$ despite use of bDMARDs; Class $2(n=314)$, patients with a consistently moderate score of 0.7$)$; Class $3(n=229)$, patients whose score improved from 0.7 to 0.9 after use of bDMARDs; and Class 4 (n $=82$ ), patients with a consistently high score of 0.9. When comparing the patients in Classes 2 and 3, whose EQ-5D scores before bDMARD use were similar, the patients in Class 3 had a younger age $(p<0.001)$, shorter disease duration $(p<0.001)$, higher DAS28 score $(p<0.001)$, lower $\mathrm{J}$-HAQ score $(p=0.038)$, and more frequent use of non-steroidal agents $(p=0.002)$ than those of Class 2 patients.

Conclusion: The results of this study suggest that QOL is less likely to improve in patients with RA whose disabilities and QOL deterioration have already become established despite use of bDMARDs. We also determined the clinical features of RA patients whose QOL improved after initiation of bDMARDs.

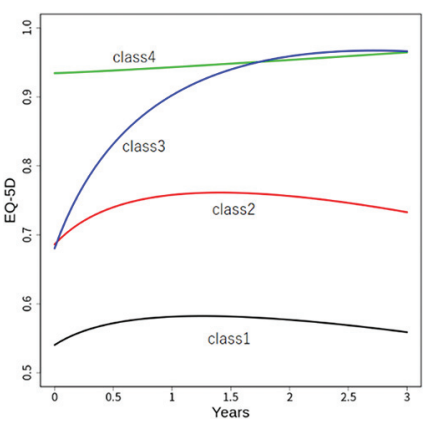

Disclosure of Interests: Kumiko Saka: None declared, Eiichi Tanaka Speakers bureau: Abbvie, Asahi Kasei pharma co., Bristol Myers Squibb, Chugai Pharmaceutical, Daiichi Sankyo Co., Eisai Pharmaceutical, Janssen Pharmaceutical K.K., Nippon Kayaku, Pfizer, Takeda Pharmaceutical, Taisho Toyama Pharmaceutical Co., and UCB Pharma., Eisuke Inoue: None declared, Mai Abe: None declared, Mika Kawano: None declared, Eri Sugano: None declared, Naohiro Sugitani: None declared, Moeko Ochiai: None declared, Yoko Shimizu: None declared, Rei Yamaguchi: None declared, Naoki Sugimoto: None declared, Katsunori Ikari: None declared, Ayako Nakajima Grant/research support from: Asahi Kasei pharma co., Chugai Pharmaceutical, Daiichi Sankyo Co., Pfizer, Kissei Pharmaceutical Co., and Mitsubishi Tanabe Pharma Corporation., Atsuo Taniguchi: None declared, Hisashi Yamanaka Grant/research support from: AbbVie, Eisai, Bristol-Meyers, Novartis, Behringer, Astellas, Kaken, Nippon-Shinyaku, Pfizer, UCB, Ayumi, Ono, Daiichi-Sankyo, Taisyo-Toyama, Takeda, Tanabe-Mitsubishi, Chugai, Teijin Pharma, Torii, YLbio, Speakers bureau: Bristol-Meyers, Astellas, Pfizer, Daiichi-Sankyo, Takeda, TanabeMitsubishi, Chugai, Teijin Pharma, YLbio DOI: 10.1136/annrheumdis-2019-eular.5220

\section{FRI0116}

SUBCUTANEOUS TOCILIZUMAB IN MONOTHERAPY OR IN COMBINATION WITH CSDMARD IN PATIENTS WITH MODERATE TO SEVERE RHEUMATOID ARTHRITIS: OBSERVATIONAL STUDY TO DESCRIBE REAL-WORLD DRUG RETENTION RATE AT 12 MONTHS

Alain Saraux ${ }^{1}$, Thomas Barnetche ${ }^{2}$, Guy Baudens ${ }^{3}$, Isabelle Idier $^{4}$

Flore Delaporte ${ }^{5}$, Pascal Hilliquin $6 .{ }^{1}$ University Hospital La Cavale Blanche,

Rheumatology, Brest, France; ' ${ }^{2}$ University Hospital of Bordeaux, Rheumatology, Biostatistics, Bordeaux, France; ${ }^{3}$ Private practice, Rheumatology, Valenciennes, France; ${ }^{4}$ Chugai Pharma France, Medical, Paris La Défense, France; ${ }^{5}$ TandM STATS, on behalf of Roche, Statistics, Boulogne-Billancourt, France; ${ }^{6} \mathrm{Hôp}$ ital Sud Francilien, Rheumatology, Corbeil-Essonne, France

Background: Rate of discontinuation and drug survival of biologic therapies in rheumatoid arthritis (RA) is about $60-70 \%$ in real life at one year ${ }^{1}$. In France, all biologics 1st prescription and yearly renewal are reimbursed, restricted to hospital rheumatologists, with renewal and monitoring done by both office-based or hospital rheumatologists.

Objectives: To evaluate the 12-month drug retention rate, efficacy and tolerance of tocilizumab (TCZ) subcutaneous (sc) in RA patients (pts). Study design: prospective, multicentre, observational 18-month study. Pts: moderate to severe active RA requiring TCZ $s c$ as prescribed in real life. Primary endpoint: drug retention rate of TCZ sc at 12 months in pts followed by hospital- and office-based rheumatologists, estimated using Kaplan-Meier method. Secondary endpoints: pts' characteristics, concomitant treatments, adherence to TCZ sc using the Compliance Questionnaire for Rheumatology (CQR5), efficacy, safety of TCZ sc and QoL using EQ5D. Statistical analysis: pts with $\geq 1 \mathrm{TCZ}$ injection were analyzed for safety. Pts fulfilling inclusion and non-inclusion criteria were analyzed for efficacy.

Results: 291 pts were recruited, 286 were analyzed for safety and 285 for efficacy.

Baseline: mean age $56.2 \pm 12.5$ years, females: $74.7 \%$, at least 1 co-morbidity: $71.9 \%$, mean RA duration $9.4 \pm 9.0$ years, RF and/or ACPA: $83.4 \%$, erosive RA: $60.8 \%$, mean DAS28-ESR $4.77 \pm 1.21$. Past RA treatments were csDMARDs in $94.4 \%$, biologics in $62.8 \%$. EQ-5D Health state was $0.53 \pm 0.19$. TCZ Mono (i.e. without CSDMARD) was initiated in 124 (43.5\%), TCZ Combo in $158(55.4 \%)$ pts, $84.8 \%$ of whom received MTX $(17.3 \pm 4.4 \mathrm{mg} / \mathrm{w}$ ). Glucocorticoids (GCs) were used in $48.9 \%$ of the pts $(9.99 \pm 9.36 \mathrm{mg} / \mathrm{day})$.

Follow up: 161 and 148 pts completed $\mathrm{M} 12$ and M18 visits. 138 pts withdrew including AE 61, lack of efficacy 37 , pts/doctor wish 24. At M12, drug retention rate was 63.6\%: $62.6 \%$ in Mono, $64.3 \%$ in Combo (Fig.1); with similar results for pts $\leq />65$ years old and for pts $\leq />$ $30 \mathrm{Kg} / \mathrm{m}^{2}$. 5 Mono pts had ongoing csDMARD and 9 Combo pts had no CSDMARD. $15.3 \%$ and $19.0 \%$ used GCs, $16.19 \pm 11.95 \mathrm{mg} / \mathrm{d}$ in the Mono and $17.36 \pm 16.65 \mathrm{mg} / \mathrm{d}$ in the Combo groups. Total number of TCZ injections was $36.74 \pm 25.84$ done by pt in $54.0 \%$. Mean time between 2 TCZ injections was $8.48 \pm 10.70$ days. Adherence to TCZ was high in $86.5 \%$ of the 89 pts who completed CQR5 at month 12. It was $52.9 \%$ for the 121 pts who completed pts diary over the month 12-month 18 period. Mean DAS28 in all, Mono and Combo were $1.91 \pm 1.11,1.66 \pm 1.02,2.12 \pm 1.14$ respectively. EULAR good and moderate responses were respectively 61.3 and $7.7 \%$ in all: 67.2 and $4.9 \%$ in Mono; 56.8 and $9.9 \%$ in Combo pts. EQ-5D improved in all domains with a change from baseline of 0.11 $\pm 0.29 .234(81.8 \%)$ pts had at least 1 adverse event (AE), $46(16.1 \%)$ had at least 1 serious AE including 11 infections, 2 Gl perforations and 2 deaths (pneumopathy and bronchial carcinoma).

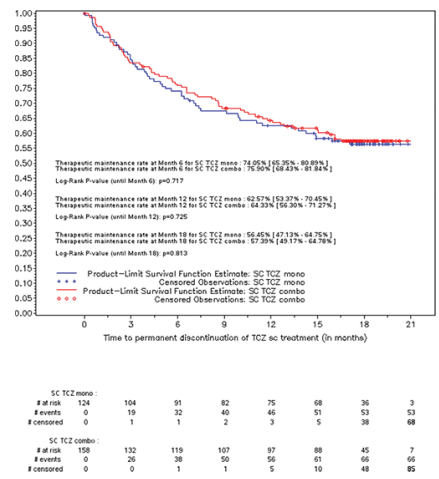

Figure 1. Kaplan-Meier curve of the drug retention rate by SC TCZ in mono vs combo Efficacy population 